\title{
A Column Experiment showing Adsorption Dynamics and kinetics of Selected PAH using Plantain and Cassava Peels
}

\author{
Uzoije Atulegwu Patrick $^{1 *}$ and Alex-Okorafor Chiwuike ${ }^{2}$ \\ 1,2 Department of Environmental Technology. Federal University of Technology \\ Owerri Nigeria \\ *atulegwuuzoije@yahoo.com
}

\begin{abstract}
Polycyclic aromatic hydrocarbons are primary organic components of crude oil, coal and other related substances. When disposed to the environment as waste by-products of refineries and coal plants, they contaminate the soil and water, causing harm to human, plants and other organisms. A simple but cost-effective technique of removing PAH at source points is now a major challenge to environmentalists. In the present study, the validity of removing selected PAH compounds - Benzo(k) fluoranthene, Acenaphthene, Fluoranthene, and Pyrene in a dynamic adsorption (flow through packed column) method was studied between 1000 to 1200 mins using activated cassava and plantain peels(ACP and APP) as adsorbents. Results show high steep slope curves indicating delayed breakthrough and high adsorption of PAH. Whereas the flat breakthrough curves and high adsorption of PAH compounds were observed at low inflow rate of PAH solutions into the column, high inflow rates produced high steep breakthrough curves and low adsorption of the compounds due to inadequate contact with the adsorbents. The adsorption process was found conforming with the kinetic models of Yoon-Nelson, AdamBohart and Thomas. It was established, from these results that the activated biosorbents $(A C P$ and $A P P)$ used as adsorbents reasonably reduced the PAH compounds, with activated cassava peel (ACP) proving more efficient than that of plantain peel (APP).
\end{abstract}

Keywords: Adsorption, Kinetic models, PAH, Plantain, Cassava, and Column experiment

\section{Introduction}

Anthropogenic sources of Polycyclic Aromatic Hydrocarbon compounds (PAHs) originate mainly from petroleum refineries, fossil fuel, power plants (coal, oil), paper mills, wood products and other related manufacturing Industries [1, 2, 3]. Other pathways include; oil spillage, aerial fallout, and through storm water runoff of PAH polluted areas. Wastes from these sources are discharged into land or water bodies, destabilizing the natural ecosystem. Record has it that United State Environmental Protection Agencies (USEPA) made a list of 16 PAHs on a priority pollutant list tagged EPS 16 PAHs [4, 5]. Due to recalcitrant tendencies of these PAH compounds, they bio-accumulate in the soils and plant tissues leading to plant contamination and consequently transfer to humans and animals through food chain. In aquatic environment, majority of PAH compounds result to liver neoplasia in fishes [6]. In human, the adverse health effects caused by these compounds range from minor eye irritation to major health complications such as cancer $[7,8]$. Previous studies revealed that most PAH compounds are resistant to biological degradation as a result of their high molecular weights and also not efficiently removed by conventional physicochemical methods such as coagulation, flocculation,

Received (December 14, 2017), Review Result (January 10, 2018), Accepted (January 16, 2018)

* Corresponding Author 
sedimentation, or ozonation process [7]. With these potential hazards associated with PAH compounds and the seeming inability of the above mentioned methods to provide enduring treatment system, it is expedient to proffer cost effective and rapid treatment mechanisms capable of reducing the compounds to the barest minimum. Although, conventional treatment systems such as membrane process, reverse osmosis, ultrafiltration and sorption filtration processes using silica gel, zeolites, and alumina materials were implemented in the past with reasonable level of successes in addressing issues of pollution of PAHs and other related compounds but had major drawback of high cost of material and operation [9]. Most recently, focus has been on adsorption process with the use of activated carbon to remove persistent organic carbon polluted wastewater. Soluble organic substances in water, which cannot be removed during conventional biological treatments or be precipitated during chemical coagulation/flocculation process, can be removed by adsorption on activated carbon. Adsorption on activated carbon has been found to give $60 \%$ removal of organic substances like 2-Methyl-isobormeal and many micro pollutants like chlorinated pesticides, phenols, etc., [10] but high cost and difficulty in regeneration of the activated carbon material after adsorption process remain a major drawback [11]. Recently, low-cost agricultural by-products have been proven as alternative adsorbents. They are ubiquitous, they have high sorption affinity, ease of being modified as adsorbent material of high efficiency, etc. [12]. A number of agricultural waste products have been developed as adsorbents to remove types of organic and inorganic pollutants of varying concentrations from wastewater [13, 14, 15, 16, 17, 18]. Of interest are the activated cassava and plantain peels (ACP and APP). These two adsorbents have also been applied in the removal of organic and inorganic pollutants. APP has been used to remove $\mathrm{Cu}(\mathrm{II}), \mathrm{Pb}(\mathrm{II}), \mathrm{Cd}(\mathrm{II}), \mathrm{Zn}$ (II) from wastewater $[19,20,21$, 22]. Also in the past, [23] (Olayiwola, et al., 2013) used ACP in treating wastewater effluents, [24] Kigho, et al., 2016 compared the adsorptive capacities of fermented and unfermented activated cassava peels in the treatment of refinery wastewater effluents. Parvath, et al., 2011 [25] studied the removals of Malachite Green using activated cassava peel. Although these applications yielded significant wastewater treatment results, but little attention has been given to the validity of applying APP and ACP adsorbents to remove PAHs compounds from polluted water. In the present study therefore, activations of cassava and plantain peels and investigations on their efficacies in treating $\mathrm{PAH}$ polluted water were carried out.

A prominent bitumen refinery situated at Oyigbo South-South Nigeria channels its effluent into a nearby wetland. The waste has devastated the entire wetland and the nearby creeks, with visible traces of bitumen on the surface of the water bodies. Bitumen is composed mainly of highly condensed Polycyclic Aromatic Hydrocarbons (PAHs). Studies have shown that PAHs have been documented to cause several health problems [18]. It is important to safe guard the wetland from the pollution-induced destruction by the refinery effluent through the provision of low cost and effective treatment system. This study therefore, aims to assess the validity of applying APP and ACP adsorbents to remove some selected $\mathrm{PAH}$ compounds from the bitumen refinery effluent.

\section{Materials and Methods.}

\subsection{Effluent Water Sample Collection and Analysis}

Water effluent samples from the bitumen refinery were collected in three replicates for analysis. The samples were analyzed for the sixteen PAHs on a priority list of pollutants usually referred to as EPA $16 \mathrm{PAH}$ [5]. The analysis was carried out using Gas Chromatography (GC) method equipped with a Flame Ionization Detector (FID).The average values of various $\mathrm{PAH}$ in the respective samples were used as the initial concentrations used in the dynamic adsorption simulation. 


\subsection{Adsorbent Preparation and Activation}

Plantain and cassava peels were collected from the market in Aba Abia state. The peels were washed, sun dried for 72 hours, further dried at $110^{\circ} \mathrm{C}$ for 24 hours with SANFA DHQ-9101-1 SA. The dried peels were ground separately and sieved to a size of $425 \mu \mathrm{m}$. Thereafter, $200 \mathrm{~g}$ of each dried, ground and sieved peel was put in separate flask containing $550 \mathrm{ml}$ of $\mathrm{HCl}$ and stirred until a paste is formed. The paste was oven dried at $110^{\circ} \mathrm{C}$ for 48 hours when complete dryness was achieved. After cooling, the adsorbents were washed with distilled water to achieve $\mathrm{P}^{\mathrm{H}}$ neutrality of 7 before drying, final grinding and sieving took place.

\subsection{Characterization of the Adsorbents}

Bulk density, porosity, ash content, surface area, particle size, cellulose and $\mathrm{PH}$ were determined using standard methods, the functional groups and pore sizes of the adsorbents were determined before and after the simulation using Fourier transform infrared (FTIR) spectroscopy and Scanning electron microscopy (SEM) respectively.

\subsection{Experimental Procedure}

A scinter glass filter of stainless steel was placed at the bottom of the glass column $4.5 \mathrm{~cm}$ diameter and $25 \mathrm{~cm}$ height used for this experiment. Also, a glass wool was placed above the glass filter to forestall the loss of the adsorbent. Subsequently, 20g of ACP was introduced into the set-up and compressed to $12 \mathrm{~cm}$ before the $100 \mathrm{ml}$ wastewater effluent of pre-determined initial concentration from the bitumen refinery was poured to the brim of the cylinder clamped with a retort stand. With the help of the prestaltic pressure pump, the wastewater passed through the column and exited as effluent at $10 \mathrm{ml} / \mathrm{min}$ into the beaker.

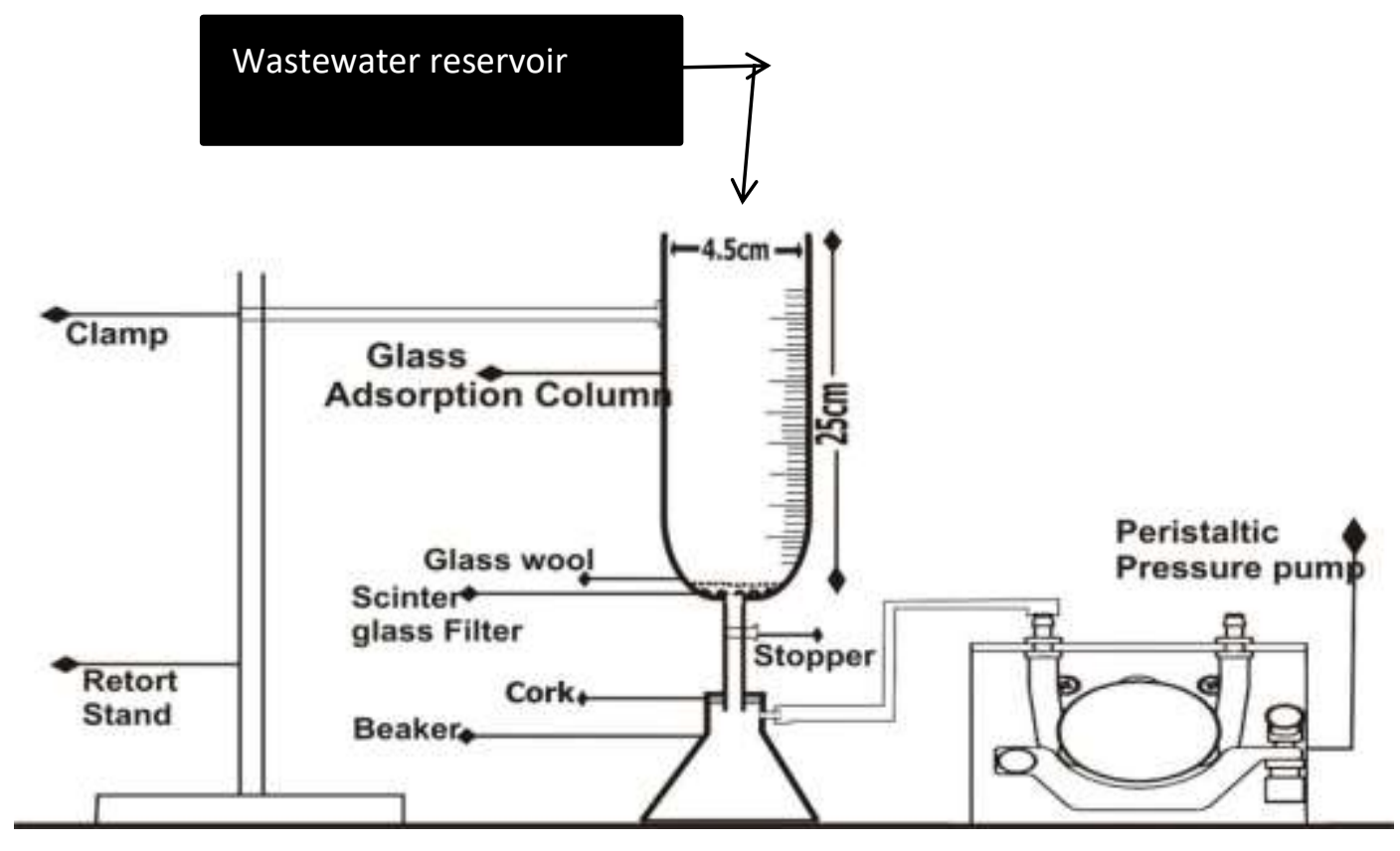

Figure 1. Set-up for the Column Experiment

The effluent was collected at different time intervals for analysis until at breakthrough concentration. The set-up is show on Figure 1. The experiment was repeated at varying bed heights of 9 and $6 \mathrm{~cm}$ and at the flow rates of 5 and $3 \mathrm{ml} / \mathrm{min}$. The same experimental procedure was carried out using ACP as adsorbent 


\subsection{The Kinetic Analysis of the Data}

The dynamics of flow and adsorption of PAH compounds on the two adsorbents (ACP and APP) under study were investigated based on the data obtained. Use was made of the Yoon-Nelson, Thomas and Adam-Bohart models for the analysis. The data obtained from the column experiment were analyzed by the models based on the concentration ratio $\left(C_{t} / C_{O}\right)$ of the adsorbing compounds and time of adsorption.

\subsubsection{Yoon-Nelson}

The linearized form of this model is stated as follows,

$$
\ln \left(\frac{C_{t}}{C_{o}+C_{t}}\right)=K_{Y N} t-\tau K_{Y N} \ldots \ldots \ldots
$$

The data obtained from column experiment were put into this model to study the breakthrough behavior of PAH compound through ACP and APP adsorbent materials. The model parameters which are defined as ; $k \mathrm{YN}(\min -t t)$, the rate constant and $\tau$, the time required for $50 \%$ adsorbate breakthrough were determined in relation to PAH adsorptions on the adsorbents by plotting In $\left(\mathrm{C} / \mathrm{C}_{0}-\mathrm{C}_{\mathrm{t}}\right)$ versus time..

\subsubsection{Thomas Model}

The Model was used in a linearized form to assess its suitability to the obtained data. The linearlized form of the equation is expressed as follows;

$$
\ln \left(\frac{\mathrm{C}_{o}}{C_{t}}-1\right)=\frac{K_{t h} q_{o} m}{Q}-K_{t h} C_{o} t
$$

Where $K_{t h}, q_{o} \mathrm{C}_{o}, C_{t}, t$ and $m$ represent the Thomas rate constant, maximum uptake capacity of the PAH per $\mathrm{g}$ of the adsorbents, inflow and outflow concentration of the PAH, time of adsorption and mass of the adsorbents respectively. $K_{t h}$ and $q_{o}$ Model parameters were determined through the slope and gradient of the curve obtained by plotting $\frac{\mathrm{C}_{o}}{C_{t}} \quad V s t$. The parameter values were obtained at various inflow rates and PAH components,

\subsubsection{Adams Bohart}

Adams Bohart model was also used to describe the breakthrough curve of the sorption process. The model is expressed as follows;

$$
\ln \left(\frac{\mathrm{C}_{o}}{C_{t}}-1\right)=K_{A B} N_{o} \frac{Z}{F}-K_{A B} C_{o} t \ldots \ldots
$$

Where the following; $K_{A B}, N_{o} \mathrm{C}_{o}, C_{t}, t, Z$ and $F$ represent Adam-Bohart rate constant, maximum concentration, initial concentration, concentration at time, $t$, bed height and inflow rate respectively. Plots of $\ln \left(\frac{C_{o}}{C_{t}}-1\right) V s t$ at varying flow rates and constant bed height produced slopes and gradients in which the model parameters $\left(, N_{o}\right.$, and $K_{A B}$ ) describing the performance of the sorption column were determined.

\section{Results}

\subsection{PhysicalCharacteristic}

Table 1 shows the physicochemical properties of ACP and APP. There were glaring variations in the values of the physicochemical parameters of the two adsorbents. APP seems to have higher bulk density and ash content than ACP whereas ACP has higher porosity, surface area, cellulose values than APP 
Table 1. Physical Characteristics of Adsorbents (ACP and APP)

\begin{tabular}{|l|l|l|l|}
\hline S/N & PARAMETERS & $\begin{array}{l}\text { ACTIVATED } \\
\text { CASSAVA PEELS }\end{array}$ & $\begin{array}{l}\text { ACTIVATED } \\
\text { PLANTAIN PEELS }\end{array}$ \\
\hline 1 & Bulk Density, $\mathrm{g} / \mathrm{cm}^{3}$ & 0.596 & 0.666 \\
\hline 2 & Porosity & 0.46 & 0.43 \\
\hline 3 & Particle Size, $\mu \mathrm{m}$ & 425 & 425 \\
\hline 4 & Surface Area, $\mathrm{cm}^{2} / \mathrm{g}$ & 236.87 & 211.98 \\
\hline 5 & Ash Content, $\%$ & 2.46 & 4.47 \\
\hline 6 & Cellulose, $\mathrm{g} / \mathrm{g}$ & 0.39 & 0.28 \\
\hline 7 & $\mathrm{pH}$ & 6.3 & 5.9 \\
\hline
\end{tabular}

Results of the surface chemistry of the two adsorbents involving pore sizes and the functional groups before and after column adsorption simulations were shown Figures 2a$\mathrm{b}$ and 3a-b respectively. Looking at the figures, fibrous materials have rough edges and irregular surfaces in both adsorbents. However, larger pore space distributions were observed on SEM microgram of ACP than on that of APP. It has been observed that numerous pore space distributions suggests high adsorption capacity [22]. On further magnification of SEM microgram of both adsorbents after simulation, the pore spaces disappeared, revealing ridges.

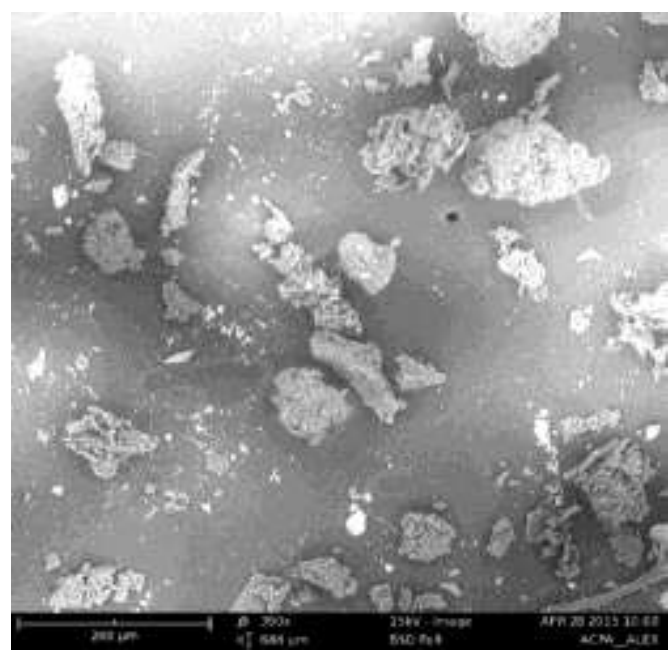

(a)

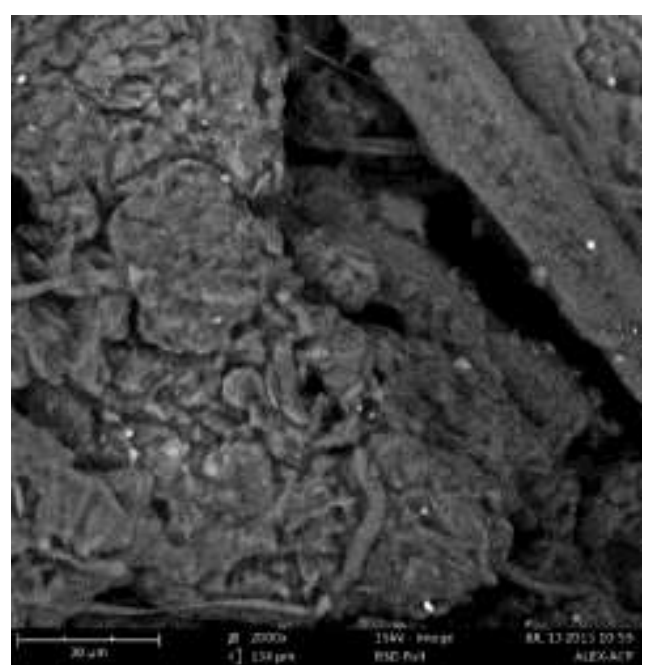

(b)

Figures 2. $a$ and b SEM Micrographs of ACP before Adsorption and after Adsorption 

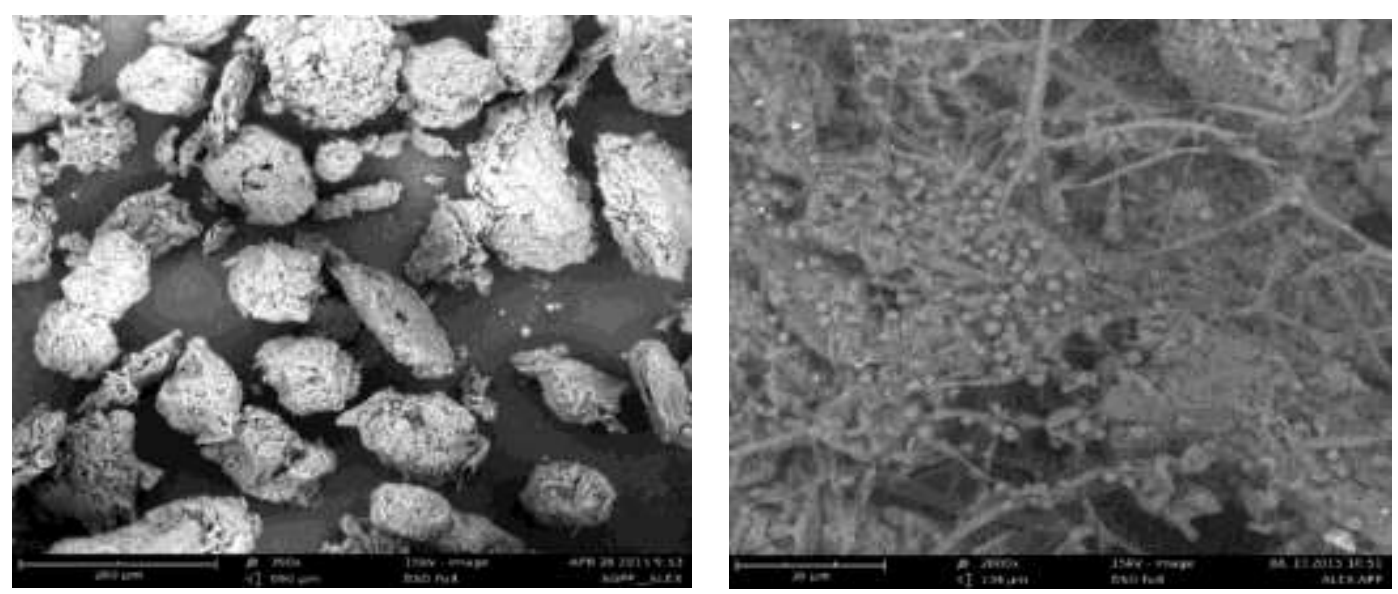

Figures 3a-b. (3a) SEM Micrographs of APP before Adsorption and (3b) after Adsorption

The absence of pore spaces indicated coverage of the pores by PAH molecules. In $\mathrm{ACP}$, the pore spaces were virtually absent because of total coverage of PAH molecules whereas partial coverage was observed on PAH molecular cloud.

\section{Adsorption capacity of the adsorbents;}

Studies on adsorption capacity of ACP and APP to determine the amount of pronounced PAH compounds (Benzo(k) fluoranthene, Acenaphthene, Fluoranthene, and Pyrene) adsorbed on the two adsorbents were carried out and the trends of adsorption were shown on Figures 4a-d. Generally, adsorption capacity of the adsorbents decreased with time until at saturation point when adsorption attained equilibrium. However, there were glaring variations in abilities of the adsorbents to uptake PAH compounds. In the figures, PAH adsorption curves for ACP is less steep than that of APP, suggesting that PAH compounds had longer contact time with ACP adsorbent with consequent high PAH uptake. Adsorption affinity for various PAH compounds to the adsorbing materials (ACP and APP) is represented on Figure 5a-b. The result shows that the adsorption affinity of PAH compounds are at variance with one another. Acenaphthene has the highest affinity with Fluoranthene having the least affinity to both ACP and APP.
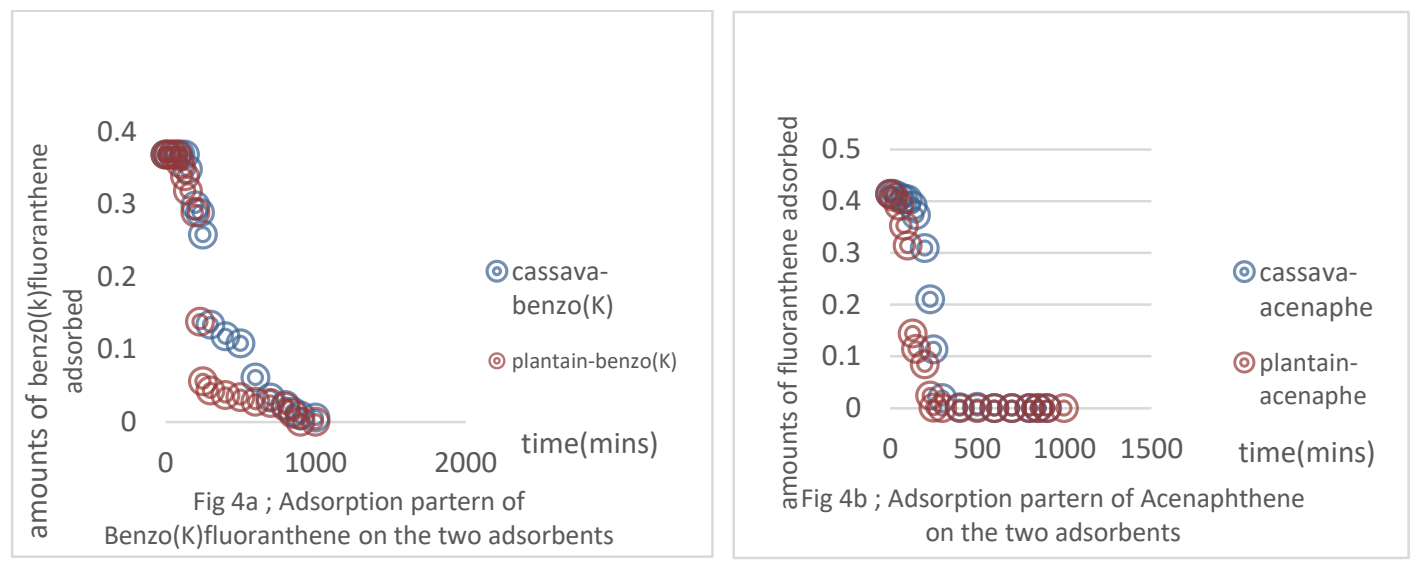

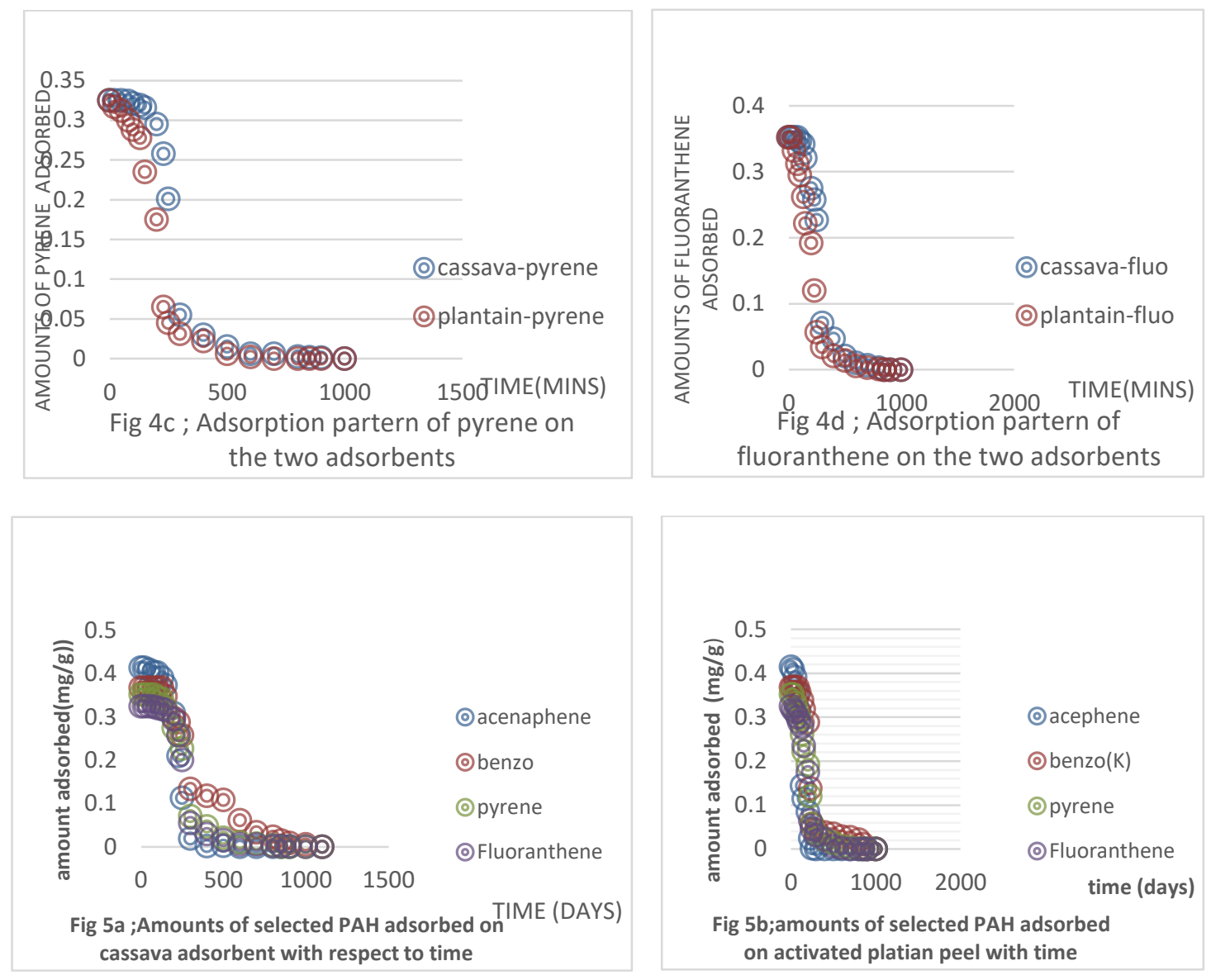

The order of adsorption affinity of the PAH compounds is represented as; Acenaphthene $>$ Benzo(k)fluoranthene $>$ Pyrene, $>$ Fluoranthene.

\subsection{Chemical Characteristic}

The FTIR spectra of ACP and APP adsorbents before and after adsorption are shown on Figures 6a-b and 7a-b respectively. Several Adsorption bands were observed in FTIR spectra of the two adsorbents. In ACP spectrum, distinct adsorption bands between 553.59 $\mathrm{cm}^{-1}$ and $659.68 \mathrm{~cm}^{-1}, 1026.16 \mathrm{~cm}^{-1}$ and $1243.16 \mathrm{~cm}^{-}, 1545.03 \mathrm{~cm}^{-1}$ and $1640.51 \mathrm{~cm}^{-1}$, $3216.41 \mathrm{~cm}^{-1}$ and $3378.43 \mathrm{~cm}^{-1}$ correspond to $\mathrm{C}-\mathrm{Br}$ stretch vibrations, $\mathrm{C}=\mathrm{O}$ stretch, $\mathrm{N}-\mathrm{H}$ deformation and $\mathrm{O}-\mathrm{H}$ stretch respectively were prominent.

These functional groups are ready binding and oxidative sites for hydrocarbon $[4,15$, 16, 7]. After adsorption of PAHs, glaring changes were observed on the ACP spectrum. New peaks were observed, some peaks were shifted while some completely disappeared. These changes signify interaction with the adsorbate (PAHs). Alkyl halides, alkenes, alkynes, amino and nitro compounds were observed after adsorption as against the presence of carboxyl, hydroxyl and carbonyl groups (adsorptive sites) observed before the sorption process. It was obvious that chemical reactions of oxidation and reduction with PAH compound and displacement of certain substances took place in the course of adsorption [22]. Also, peaks at $1026.16 \mathrm{~cm}^{-1}$ and $3216.41 \mathrm{~cm}^{-1}$ representing $\mathrm{C}=\mathrm{O}$ and $\mathrm{O}-\mathrm{H}$ were completely absent after adsorption. 


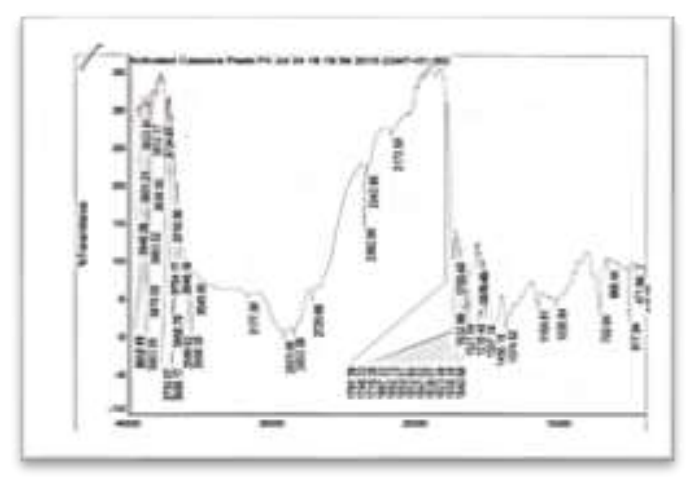

(a)

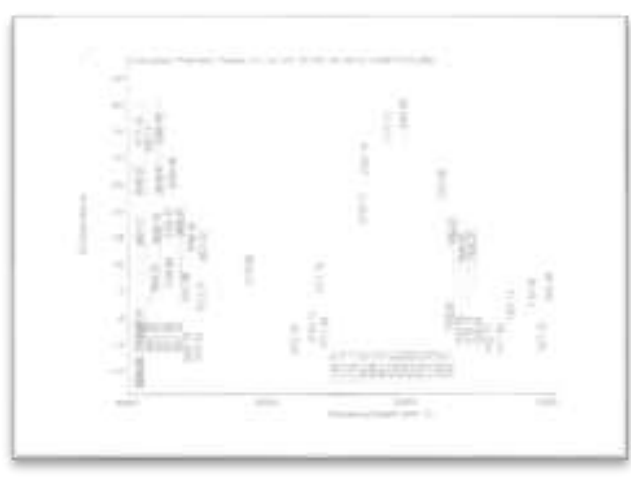

(b)

Figure 6a-b. FTIR Spectra of ACP before (6a) and after (6b) Adsorption

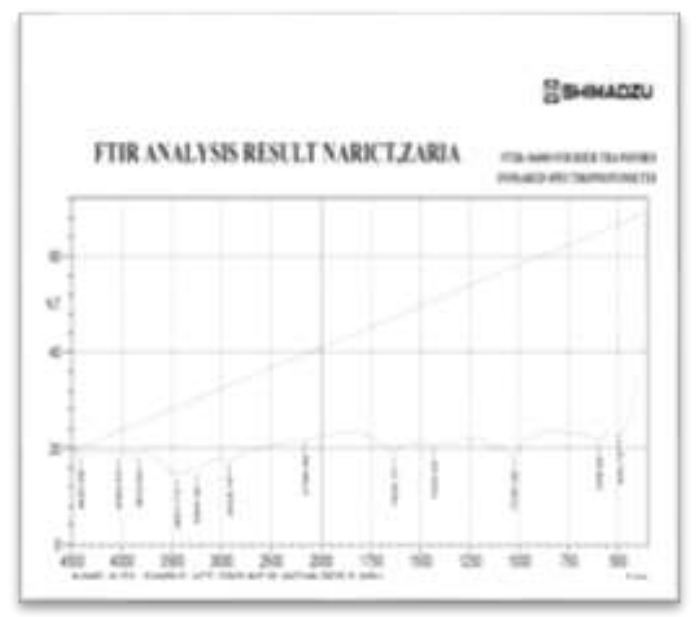

(a)

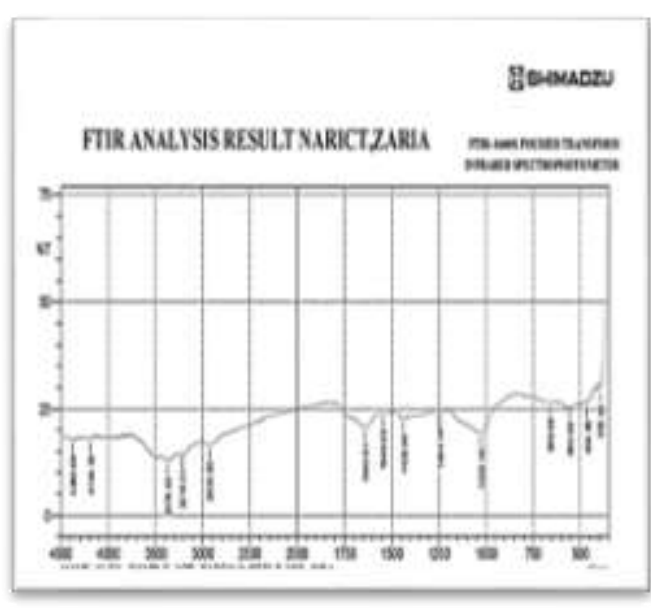

(b)

Figure 7a-b. FTIR Spectra of APP before (7a) and after (7b) Adsorption

\subsection{Breakthrough Curves of Various Adsorbents}

Unlike the batch process, adsorption equilibrium in column or fixed bed is continuous because not every section of the bed gets saturated at the same time. If a solution is introduced in the fixed bed or column, it creates a wave front as it moves down the column. Overtime, saturation and mass transfer zones are formed in the column as the solution moves through the column. The section of the column which has been completely covered by the wave front that is, behind the wave front is referred to as the saturated zone. Sections of the fixed bed partially covered by the wave front are termed the Mass transfer zone. Unlike in the saturated zone, adsorption process is usually in progress at this zone until it is completely saturated. As the mass transfer zone moves forward towards the out let of the column, it leaves behind zones of saturation until at a point the entire column is fully saturated. At this point equilibrium of the fixed bed is said to have been attained, hence the breakthrough point. The pattern of movement of mass transfer zone through the fixed bed is represented as the breakthrough curve. In this study, breakthrough curves were studied by loading of PAH compound in various ACP and APP packed beds at varying bed heights and flow rates

\subsubsection{Influence of Bed Height}

The PAH compound polluted wastewater was loaded into the adsorption column at varying bed heights of $6 \mathrm{~cm}, 9 \mathrm{~cm}$ and $12 \mathrm{~cm}$ to study the breakthrough curves at various 
bed heights. Figures 8a-b show variations in the shape of the breakthrough curves for ACP and APP adsorbents. For brevity, the figures only show that of Acenaphen. The steepness of the breakthrough curves seem to vary inversely with bed heights. From the figures, Curve steepness is high at bed height of $6 \mathrm{~cm}$ and decreased through $9 \mathrm{~cm}$ to the lowest at bed height $12 \mathrm{~cm}$.

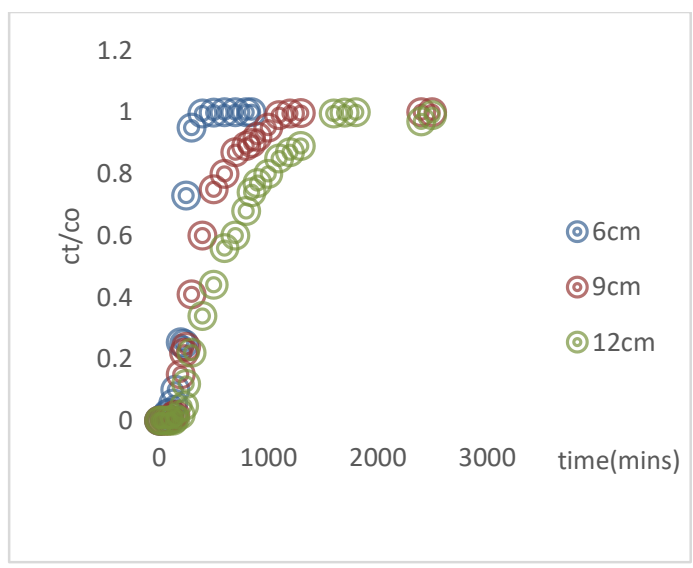

Figure 8a. Effects of Varying Bed Hieghts on Acenaphen Adsorption onto ACP

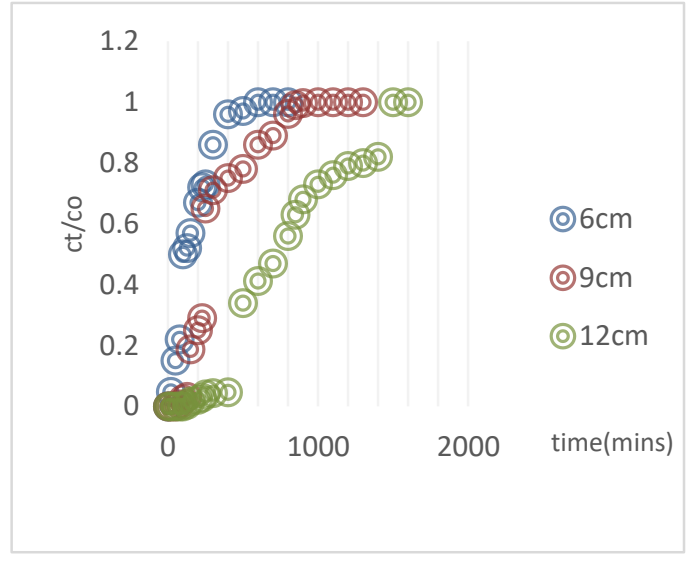

Figure 8b. Effects of Bed Hieghts on the Breakthrough Curves of Adsorption of Acenaphen onto APP

\subsubsection{Effects of Flow Rate}

Breakthrough curves obtained by varying the inlet flow rate of the PAH polluted wastewater into and through the packed column ACP and APP adsorbents are show on Figures 9a-b. Again, for brevity, only breakthrough curves for Acenaphen are shown. The inlet flow rates varied at 3,5 and $10 \mathrm{ml} / \mathrm{min}$ produced different shapes of breakthrough curves.

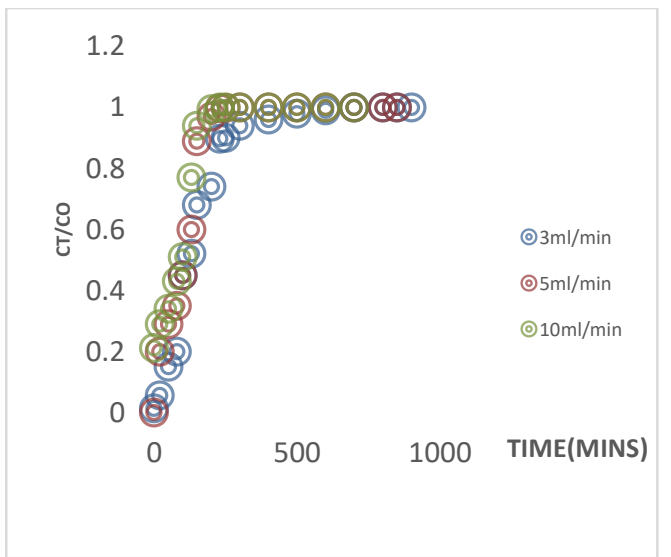

Figure 9a; Effects of Flow Rate on Breakthrough Curves for Acenaphene APP

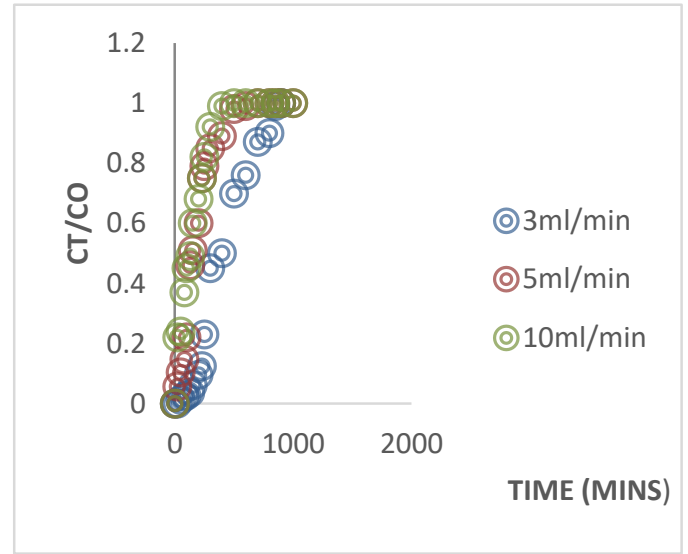

Figure 9b; Effects of Flow Rate on Breakthrough Curves for Acenaphene ACP 
The highest flow rate of $10 \mathrm{ml} / \mathrm{min}$ resulted to quick breakthrough of the wastewater hence high steep breakthrough curve. At lower inlet flow rates of $6 \mathrm{ml} / \mathrm{min}$ and $3 \mathrm{ml} / \mathrm{min}$ PAH compounds experienced slow breakthrough with low breakthrough curve steepness. The packed bed column experienced the slowest breakthrough hence lowest breakthrough curve steepness at inlet flow rate of $3 \mathrm{ml} / \mathrm{min}$

\subsubsection{Kinetic Study}

The results of the kinetic study showing the values of model parameters determined at various inlet flow rates and bed heights are presented on tables 2-4. The values for YoonNelson model parameters varied significantly among various adsorbents, PAH compounds and input variables. For example, time required for 50\% breakthrough, increased with decrease in the flow rate values at constant bed height. The rate constant, $\mathbf{K}_{\mathbf{Y N}}$ seems to decrease with decrease in flow rate. Also, higher $\mathbf{K}_{\mathbf{Y N}}$ values were observed during sorption process of the investigated PAH with ACP than APP adsorbent. Correlation coefficient values were equally high in all the sorption runs with the adsorbents (PAHs).

Table 2. Yoon - Nelson Model Parameters

Benzo(k)fluoranthene

\begin{tabular}{|l|l|l|l|l|l|l|l|}
\hline $\begin{array}{l}\text { Flow } \\
\text { Rate } \\
(\mathbf{m l} / \mathbf{m i n})\end{array}$ & $\mathbf{K}_{\mathbf{Y N}}$ & $\tau(\mathbf{m i n})$ & $\mathbf{R}^{2}$ & $\begin{array}{l}\text { Flow } \\
\text { Rate } \\
(\mathbf{m l} / \mathbf{m i n}\end{array}$ & $\mathbf{K}_{\mathbf{Y N}}$ & $\tau(\mathbf{m i n})$ & $\mathbf{R}^{2}$ \\
\hline ACP & \multicolumn{1}{|l|}{ APP } \\
\hline 10 & 0.040 & 130 & 0.971 & 10 & 0.025 & 122 & 0.935 \\
\hline 5 & 0.034 & 169 & 0.983 & 5 & 0.030 & 145 & 0.949 \\
\hline 3 & 0.034 & 178 & 0.976 & 3 & 0.029 & 160 & 0.972 \\
\hline
\end{tabular}

\section{Acenaphthene}

\begin{tabular}{|c|c|c|c|c|c|c|c|}
\hline \multicolumn{3}{|c|}{ ACP } & \multicolumn{4}{c|}{ APP } \\
\hline $\begin{array}{c}\text { Flow } \\
\text { rate(ml/min) }\end{array}$ & $\mathbf{K}_{\mathbf{Y N}}$ & $\begin{array}{c}\tau \\
(\mathbf{m i n})\end{array}$ & $\mathbf{R}^{\mathbf{2}}$ & $\begin{array}{c}\text { Flow } \\
\text { rate(ml/min) }\end{array}$ & $\mathbf{K}_{\mathbf{Y N}}$ & $\begin{array}{c}\tau \\
(\mathbf{m i n})\end{array}$ & $\mathbf{R}^{\mathbf{2}}$ \\
\hline 10 & 0.036 & 136 & 0.992 & 10 & 0.035 & 125 & 0.991 \\
\hline 5 & 0.034 & 183 & 0.978 & 5 & 0.030 & 151 & 0.977 \\
\hline 3 & 0.034 & 196 & 0.994 & 3 & 0.033 & 164 & 0.981 \\
\hline
\end{tabular}

Fluoranthene

\begin{tabular}{|c|c|c|c|c|c|c|c|}
\hline \multicolumn{3}{|c|}{ ACP } & \multicolumn{4}{c|}{ APP } \\
\hline $\begin{array}{c}\text { Flow } \\
\text { rate(ml/min) }\end{array}$ & $\mathbf{K}_{\mathbf{Y N}}$ & $\tau(\mathbf{m i n})$ & $\mathbf{R}^{\mathbf{2}}$ & $\begin{array}{c}\text { Flow } \\
\text { rate(ml/min) }\end{array}$ & $\mathbf{K}_{\mathbf{Y N}}$ & $\tau(\mathbf{m i n})$ & $\mathbf{R}^{\mathbf{2}}$ \\
\hline 10 & 0.037 & 159 & 0.990 & 10 & 0.033 & 133 & 0.955 \\
\hline 5 & 0.038 & 179 & 0.983 & 5 & 0.035 & 157 & 0.966 \\
\hline 3 & 0.031 & 201 & 0.992 & 3 & 0.034 & 193 & 0.964 \\
\hline
\end{tabular}




Pyrene
\begin{tabular}{|c|c|c|c|c|c|c|c|}
\hline \multicolumn{3}{|c|}{ ACP } & \multicolumn{4}{c|}{ APP } \\
\hline $\begin{array}{c}\text { Flow } \\
\text { rate(ml/min) }\end{array}$ & $\mathbf{K}_{\mathbf{Y N}}$ & $\begin{array}{c}\tau \\
(\mathbf{m i n})\end{array}$ & $\mathbf{R}^{\mathbf{2}}$ & $\begin{array}{c}\text { Flow } \\
\text { rate(ml/min }\end{array}$ & $\mathbf{K}_{\mathbf{Y N}}$ & $\begin{array}{c}\boldsymbol{\tau} \\
(\mathbf{m i n})\end{array}$ & $\mathbf{R}^{\mathbf{2}}$ \\
\hline 10 & 0.045 & 148 & 0.982 & 10 & 0.033 & 131 & 0.978 \\
\hline 5 & 0.036 & 193 & 0.993 & 5 & 0.034 & 155 & 0.987 \\
\hline 3 & 0.034 & 193 & 0.980 & 3 & 0.033 & 188 & 0.976 \\
\hline
\end{tabular}

Thomas model parameters shows that the Values of maximum uptake capacity $\left(q_{o}\right)$ and rate constants $\left(K_{t h}\right)$ of various PAH compounds are higher in ACP than APP. The values of $\left(q_{o}\right)$ increased with decrease in the in-flow rate of PAH solution but rate constants $\left(K_{t h}\right)$ values inversely related with inflow rates. In addition, reasonable model fitness to the data was also observed with high values of correlation coefficient. Among the adsorbates, that is the PAHs understudy, variations in $\left(q_{o}\right)$ and $\left(K_{t h}\right)$ were also observed. Although with slight difference, the maximum uptake capacity of the PAHs among each adsorbent (ACP and APP) was observed but the uptake capacity values were quite phenomenal when juxtapose with the two adsorbents.

Table 3. Thomas Model Parameters

Benzo (k) fluoranthene

\begin{tabular}{|c|c|c|c|c|c|c|c|}
\hline \multicolumn{4}{|c|}{$\mathbf{A C P}$} & \multicolumn{4}{|c|}{ APP } \\
\hline $\begin{array}{l}\text { Flow rate } \\
\mathrm{Q}(\mathrm{m} / \mathrm{min})\end{array}$ & $\begin{array}{l}\mathbf{K}_{\mathrm{T}}(\mathbf{m l} / \\
\mathrm{min} / \mathbf{m} \\
\text { g) }\end{array}$ & $\begin{array}{l}q_{0} \\
(\mathrm{mg} / \mathrm{g}\end{array}$ & $\mathbf{R}^{2}$ & $\begin{array}{l}\text { Flow } \\
\text { rate } \\
\mathbf{Q}(\mathbf{m} / \mathbf{m i} \\
\text { n) }\end{array}$ & $\begin{array}{l}\mathrm{K}_{\mathrm{T}}(\mathrm{ml} / \\
\mathrm{min} / \mathrm{m} \\
\mathrm{g}\end{array}$ & $\begin{array}{l}\mathbf{q}_{0} \\
(\mathrm{mg} / \mathrm{g})\end{array}$ & $\mathbf{R}^{2}$ \\
\hline 10 & 0.097 & $` 19.13$ & 0.971 & 10 & 0.034 & 15.56 & 0.822 \\
\hline 5 & 0.082 & 29.05 & 0.982 & 5 & 0.058 & 15.07 & 0.907 \\
\hline 3 & 0.082 & 39.99 & 0.976 & 3 & 0.058 & 52.37 & 0.942 \\
\hline
\end{tabular}

Acenaphthene

\begin{tabular}{|l|l|l|l|l|l|l|l|}
\hline \multicolumn{3}{|c|}{ ACP } & \multicolumn{4}{c|}{ APP } \\
\hline $\begin{array}{l}\text { Flow } \\
\text { rate } \\
\begin{array}{l}\text { Q(m/min } \\
)\end{array}\end{array}$ & $\begin{array}{l}\mathbf{K}_{\mathbf{T}}(\mathbf{m l} / \\
\mathbf{m i n} / \mathbf{m} \\
\mathbf{g})\end{array}$ & $\begin{array}{l}\mathbf{q}_{\mathbf{0}} \\
(\mathbf{m g} / \mathbf{g})\end{array}$ & $\mathbf{R}^{\mathbf{2}}$ & $\begin{array}{l}\text { Flow } \\
\text { rate } \\
\mathbf{Q}(\mathbf{m} / \mathbf{m i n} \\
)\end{array}$ & $\begin{array}{l}\mathbf{K}_{\mathbf{T}}(\mathbf{m l} / \mathbf{m} \\
\mathbf{i n} / \mathbf{m g}\end{array}$ & $\mathbf{q}_{\mathbf{0}} \mathbf{( m g / g )}$ & $\mathbf{R}^{\mathbf{2}}$ \\
\hline 10 & 0.098 & 19.04 & 0.971 & 10 & 0.034 & 13.56 & 0.992 \\
\hline 5 & 0.092 & 20.87 & 0.982 & 5 & 0.058 & 20.07 & 0.978 \\
\hline 3 & 0.092 & 29.06 & 0.976 & 3 & 0.058 & 22.37 & 0.994 \\
\hline
\end{tabular}

\section{Fluoranthene}

\begin{tabular}{|c|l|l|l|l|l|l|l|}
\hline \multicolumn{3}{|c|}{ ACP } & \multicolumn{4}{c|}{ APP } \\
\hline $\begin{array}{l}\text { Flow rate } \\
\mathrm{Q}(\mathrm{m} / \mathrm{min})\end{array}$ & $\begin{array}{l}\mathrm{K}_{\mathrm{T}}(\mathrm{ml} \\
/ \mathrm{min} / \\
\mathrm{mg})\end{array}$ & $\begin{array}{l}\mathrm{q}_{0} \\
(\mathrm{mg} / \mathrm{g})\end{array}$ & $\mathrm{R}^{2}$ & $\begin{array}{l}\text { Flow rate } \\
\mathrm{Q}(\mathrm{m} / \mathrm{min})\end{array}$ & $\begin{array}{l}\mathrm{K}_{\mathrm{T}}(\mathrm{ml} \\
/ \mathrm{min} / \\
\mathrm{mg}\end{array}$ & $\begin{array}{l}\mathrm{q}_{0} \\
(\mathrm{mg} / \mathrm{g})\end{array}$ & $\mathrm{R}^{2}$ \\
\hline 10 & 0.11 & $` 13.9$ & 0.990 & 10 & 0.067 & 12.84 & 0.970 \\
\hline 5 & 0.11 & 19.56 & 0.983 & 5 & 0.087 & 16.83 & 0.985 \\
\hline 3 & 1.80 & 31.98 & 0.992 & 3 & 1.093 & 19.26 & 0.971 \\
\hline
\end{tabular}


Pyrene

\begin{tabular}{|c|c|c|c|c|c|c|c|}
\hline & \multicolumn{3}{|c|}{$\mathbf{A C P}$} & \multicolumn{4}{|c|}{ APP } \\
\hline $\begin{array}{l}\text { Flow rate } \\
Q(\mathrm{~m} / \mathrm{min})\end{array}$ & $\begin{array}{l}\mathbf{K}_{\mathrm{T}}(\mathbf{m l} / \\
\mathrm{min} / \mathbf{m} \\
\mathrm{g})\end{array}$ & $\begin{array}{l}\mathbf{q}_{0} \\
(\mathrm{mg} / \mathrm{g})\end{array}$ & $\mathbf{R}^{2}$ & $\begin{array}{l}\text { Flow rate } \\
Q(\mathrm{~m} / \mathrm{min})\end{array}$ & $\begin{array}{l}\mathbf{K}_{\mathrm{T}}(\mathbf{m l} \\
/ \mathbf{m i n} / \\
\mathbf{m g}\end{array}$ & $\begin{array}{l}q_{0} \\
(\mathrm{mg} / \mathrm{g})\end{array}$ & $\mathbf{R}^{2}$ \\
\hline 10 & 0.10 & 18.79 & 0.982 & 10 & 0.070 & 19.11 & 0.911 \\
\hline 5 & 0.11 & 16.57 & 0.993 & 5 & 0.087 & 12.36 & 0.975 \\
\hline 3 & 0.14 & 50.18 & 0.980 & 3 & 0.11 & 20.09 & 0.982 \\
\hline
\end{tabular}

Adams Bohart model analysis of the data shows that the maximum concentration of sorbed PAH compound onto various adsorption materials relates inversely to the inflow rate of the solution. The maximum concentration $\left(N_{O}\right)$ of PAHs sorbed onto ACP was higher than that of APP. There were also variations of Adams Bohart constant $\left(K_{A B}\right)$ with the adsorbents and adsorbates. $\left(K_{A B}\right)$ Value increased with decrease in the flow rate but increased with the value of maximum concentration. The values of the correlation coefficient indicate a good fitness of the experimental data with the model.

Table 4. Adams-Bohart Parameters

$\operatorname{Benzo}(k)$ fluoranthene

\begin{tabular}{|l|c|c|c|c|c|l|l|l|l|l|l|l|}
\hline $\begin{array}{l}\text { Flow } \\
\text { Rate } \\
(\mathbf{m l} / \mathbf{m i n})\end{array}$ & $\boldsymbol{U}_{\boldsymbol{O}}$ & $\boldsymbol{K}_{\boldsymbol{A}}$ & $\boldsymbol{N}_{\boldsymbol{O}}$ & $\boldsymbol{C}_{\boldsymbol{O}}$ & $\mathbf{R}^{2}$ & $\begin{array}{l}\text { Flow } \\
\text { Rate } \\
(\mathbf{m l} / \mathbf{m i n}\end{array}$ & $\boldsymbol{U}_{\boldsymbol{O}}$ & $\boldsymbol{K}_{\boldsymbol{A}}$ & $\boldsymbol{N}_{\boldsymbol{O}}$ & $\boldsymbol{C}_{\boldsymbol{O}}$ & $\mathbf{R}^{2}$ \\
\hline $\mathbf{A C P}$ & 2.15 & 0.046 & 77 & 0.41419 & 0.954 & 10 & 2.15 & 0.034 & 69 & 0.41419 & 0.822 \\
\hline 10 & 1.71 & 0.056 & 78 & 0.41419 & 0.934 & 5 & 1.71 & 0.058 & 72 & 0.41419 & 0.907 \\
\hline 5 & 1.44 & 0.062 & 80 & 0.41419 & 0.938 & 3 & 1.44 & 0.058 & 77 & & 0.942 \\
\hline 3 &
\end{tabular}

Acenaphthene

\begin{tabular}{|c|c|c|c|c|c|c|c|c|c|c|c|}
\hline 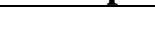 & \multicolumn{5}{|c|}{$\mathbf{A C P}$} & \multicolumn{6}{|c|}{ APP } \\
\hline $\begin{array}{c}\text { Flow } \\
\text { rate(ml/ } \\
\text { min) }\end{array}$ & $U_{o}$ & $\begin{array}{ll}K & A B\end{array}$ & $N_{0}$ & $\boldsymbol{C}_{\boldsymbol{o}}$ & $\mathbf{R}^{2}$ & $\begin{array}{c}\text { Flo } \\
\text { w } \\
\text { rate( } \\
\text { ml/ } \\
\text { min) }\end{array}$ & $U_{O}$ & $\begin{array}{ll}K & A B\end{array}$ & $N_{o}$ & $C_{o}$ & $\mathbf{R}^{2}$ \\
\hline 10 & 2.15 & $\begin{array}{c}0.05 \\
2\end{array}$ & $\begin{array}{l}6 \\
7 \\
\end{array}$ & $\begin{array}{c}0.368 \\
24\end{array}$ & 0.941 & 10 & $\begin{array}{c}2.1 \\
5 \\
\end{array}$ & $\begin{array}{c}0.05 \\
4 \\
\end{array}$ & 62 & 0.991 & 0.975 \\
\hline 5 & 1.71 & $\begin{array}{c}0.06 \\
5\end{array}$ & $\begin{array}{l}7 \\
3\end{array}$ & $\begin{array}{c}0.368 \\
24\end{array}$ & 0.940 & 5 & $\begin{array}{c}1.7 \\
1\end{array}$ & $\begin{array}{c}0.07 \\
1\end{array}$ & 66 & 0.977 & 0.962 \\
\hline 3 & 1.44 & $\begin{array}{c}0.07 \\
1\end{array}$ & $\begin{array}{l}7 \\
4\end{array}$ & $\begin{array}{c}0.368 \\
24\end{array}$ & 0.967 & 3 & $\begin{array}{c}1.4 \\
4\end{array}$ & $\begin{array}{c}0.07 \\
9\end{array}$ & 69 & 0.981 & 0.975 \\
\hline
\end{tabular}

Fluoranthene

\begin{tabular}{|c|c|c|c|c|c|c|c|c|c|c|c|}
\hline \multicolumn{6}{|c|}{ APP } & \multicolumn{6}{|c|}{ ACP } \\
\hline $\begin{array}{c}\text { Flow } \\
\text { rate } \\
(\mathbf{m l} / \mathbf{m i} \\
\text { n) }\end{array}$ & $U_{o}$ & $\begin{array}{ll}K & A\end{array}$ & $N_{o}$ & $C_{o}$ & $\mathbf{R}^{2}$ & $\begin{array}{c}\text { Flow } \\
\text { rate } \\
(\mathrm{ml} / \\
\text { min) }\end{array}$ & $U_{o}$ & $\begin{array}{ll}K & A B\end{array}$ & $N_{o}$ & $C_{o}$ & $\mathbf{R}^{2}$ \\
\hline 10 & 2.15 & 0.06 & 59 & 0.3451 & 0.92 & 10 & 66 & 0.06 & 159 & 0.3451 & 0.97 \\
\hline
\end{tabular}




\begin{tabular}{|c|c|c|c|c|c|c|c|c|c|c|c|}
\hline & & 7 & & 9 & 5 & & & 1 & & 9 & 0 \\
\hline 5 & 1.71 & 0.08 & 62 & 0.3451 & 0.96 & 5 & 66 & 0.08 & 179 & 0.3451 & 0.98 \\
& & 7 & & 9 & 1 & & & 1 & & 9 & 5 \\
\hline 3 & 1.44 & 0.07 & 73 & 0.3451 & 0.98 & 3 & 72 & 0.07 & 201 & 0.3451 & 0.97 \\
& & 8 & & 9 & 8 & & & 1 & & 9 & 1 \\
\hline
\end{tabular}

\begin{tabular}{|c|c|c|c|c|c|c|c|c|c|c|c|}
\hline \multicolumn{12}{|c|}{ Pyrene } \\
\hline \multicolumn{6}{|c|}{ ACP } & \multicolumn{6}{|c|}{ APP } \\
\hline $\begin{array}{c}\text { Flow } \\
\text { rate } \\
\text { (ml/ } \\
\text { min) }\end{array}$ & $U_{o}$ & $\boldsymbol{K} \quad \boldsymbol{A}$ & $N_{o}$ & $C_{o}$ & $\mathbf{R}^{2}$ & $\begin{array}{l}\text { Flow } \\
\text { rate } \\
(\mathrm{ml} / \\
\mathrm{min}\end{array}$ & $U_{o}$ & $\begin{array}{ll}K & A B\end{array}$ & $N_{O}$ & $C_{o}$ & $\mathbf{R}^{2}$ \\
\hline 10 & $\begin{array}{c}2.1 \\
5\end{array}$ & $\begin{array}{c}0.08 \\
0\end{array}$ & 57 & $\begin{array}{c}0.3248 \\
9\end{array}$ & $\begin{array}{c}0.88 \\
9\end{array}$ & 10 & 2.1 & 0.071 & $\begin{array}{l}5 \\
3\end{array}$ & $\begin{array}{c}0.03248 \\
9\end{array}$ & $\begin{array}{c}0.91 \\
1\end{array}$ \\
\hline 5 & $\begin{array}{c}1.7 \\
1\end{array}$ & $\begin{array}{c}0.08 \\
0\end{array}$ & 64 & $\begin{array}{c}0.3248 \\
9\end{array}$ & $\begin{array}{c}0.94 \\
0\end{array}$ & 5 & $\begin{array}{c}1.7 \\
1\end{array}$ & 0.083 & $\begin{array}{l}5 \\
8\end{array}$ & $\begin{array}{c}0.03123 \\
2489\end{array}$ & $\begin{array}{c}0.97 \\
5\end{array}$ \\
\hline 3 & $\begin{array}{c}1.4 \\
4\end{array}$ & $\begin{array}{c}0.09 \\
2\end{array}$ & 68 & $\begin{array}{c}0.3248 \\
9\end{array}$ & $\begin{array}{c}0.97 \\
5\end{array}$ & 3 & $\begin{array}{c}1.4 \\
4\end{array}$ & 0.011 & $\begin{array}{l}6 \\
6\end{array}$ & $\begin{array}{c}0.03248 \\
9\end{array}$ & $\begin{array}{c}0.98 \\
2\end{array}$ \\
\hline
\end{tabular}

\section{Discussion}

\subsection{Physical Characteristics}

The difference in the property values of these adsorbents could be attributed to different physical and chemical constitution of the two adsorbents. When compared with the values of ACP and APP properties found in the literature [25] [22][18] [13][21], variations were also observed due to carbonation effects, activation level and difference in the species of the cassava and plantain. It has been reported that the properties of adsorbents and the adsorbing material have overriding influences on the adsorption capacities of the adsorbents [22]. Previous studies attributed the seeming uptake difference to variations in physical and chemical constitutions of the adsorbents. In this study, ACP has more cellulose, porosity and surface area than APP as presented on table 1.

\subsection{Adsorbent Physical Characteristics and Adsorption Capacity}

These properties contributed to the apparent high adsorption capacity observed in ACP adsorbent because the cellulose provides high binding ability due to its rough nature [5]. Also, large hydraulic pore sizes observed in ACP adsorbent encouraged easy diffusion of the adsorbate [17] and its large surface area increased the possibility of surface heterogeneity which consequently provided greater potential for effective adsorption. Similar observations were abound in the study of [21]Olayiwola (2013).The glaring difference in pore space sizes and distributions observed in the results of the study surface chemistry of the adsorbents could be attributed to the natural effect of different adsorbent species. Previous studies affirmed that the capacity to adsorb any substance is essentially a function of the pore space distribution of the adsorbent, indicating that large pore size distribution encourages high adsorption capacity because the pore spaces create adsorption sites [22][17]. Similar observations were made in the study of Uzoije et al 2015b[20], Annadurai et al 2012 [12], and Oyekunle et al 2013[18].This buttressed the high adsorption capacity of ACP observed in the present study as against the APP which has lower pore space distribution. The reduction of the pore spaces after adsorption simulation indicates pore space coverage of various adsorbents by PAH molecules. The apparent disappearance of the pore spaces observed in the SME microgram of ACP 
further attests to the fact that more of the PAH molecules adsorbed onto the adsorbent. On the other hand, the partial PAH molecular cloud coverage on the pore spaces observed on the APP SEM microgram is an indicative of weak adsorption ability. The downward trend of adsorption affinity of the PAH molecules (Benzo(k)fluoranthene, Acenaphthene, Fluoranthene, and Pyrene) to ACP and APP with time, boarders on the saturation of the pore spaces or adsorption sites. As adsorption of PAH molecules on ACP and APP adsorbents retrogresses with time at a point, the entire adsorption sites become saturated and unable to uptake further molecules. ACP has more adsorption sites thus providing more platforms for strong affinity of the molecules than APP adsorbent. Previous studies [23][11] alluded to the availability of large pore size distribution and adsorption sites shown on ACP SEM microgram to the prevailing condition. On the other hand, adsorption curve for APP is steeper than ACP adsorption curve, implying that PAH compounds made less contact with ACP adsorbent. This might be attributed to limited active adsorption sites occasioned by low pore size distribution observed during APP surface study. The present scenario proofed less APP affinity for PAH molecular cloud and less adsorption capacity of APP adsorbent for PAHs. This explains different surface saturation periods of the adsorbents evident on adsorption capacity curves shown on Figures 5. Also, Properties of the PAH molecules play pivotal role on the amount of molecules adsorbed by the adsorbents. This assertion is buttressed in this study where various PAH compounds adsorbed at varying rate and quantity in both adsorbents as shown on Figure 6a-b. The figures, revealed that Acenaphthene showed more affinity for adsorption than the other PAHs compounds and by implication has higher adsorption amount. Acenaphthene>Benzo(k)fluoranthene>Pyrene, $>$ Fluoranthene. The perceived trend of adsorption affinity is in consonant with solubility of the PAH compounds. Due to low solubility, Acenaphthene and Benzo(k)fluoranthene precipitated thereby making their particles available to adsorption. On the other hand, Fluoranthene and Pyrene are highly soluble therefore remain more in solution. Under this condition there were fewer amounts of Pyrene and Fluoranthene available for adsorption. However, Fluoranthene is more soluble than Pyrene by virtue of structural arrangement. Fluoranthene has nonalternate arrangement hence more soluble and less susceptible to adsorption as indicated on Figures $6 \mathrm{a}$ and $6 \mathrm{~b}$. In contrast, Pyrene has alternate structural arrangement therefore less soluble than Fluoranthene [16] and by implication more susceptible to adsorption onto solid phase [17]

\subsection{Adsorbent Chemical Characteristic and Adsorption}

On the FTIR spectra of ACP and APP, the changes in the adsorption bands, shifting and erection of new peaks and complete disappearance of peaks indicated possible involvements of functional groups in the sorption process of PAHs. The main adsorption bands found in the FTIR spectrum of APP were within the peak ranges of $598.92 \mathrm{~cm}^{-1}$ $1029.06 \mathrm{~cm}^{-1} 1435.09 \mathrm{~cm}^{-1} 1634.73 \mathrm{~cm}^{-1} 3254.02-3451.73 \mathrm{~cm}^{-1}$ representing $\mathrm{C}=\mathrm{O}$ stretch, $\mathrm{C}-\mathrm{C}$ (alkane ring), N-H group, $\mathrm{C}-\mathrm{H}$ stretch and $\mathrm{O}-\mathrm{H}$ stretching vibration of hydroxylic functional groups with hydrogen bonding respectively[15]. The functional groups have strong affinity for hydrocarbons [14] and are likely to adsorb and react with PAHs. To affirm the possible interaction of PAH compounds with the adsorption sites of APP adsorbent, some peaks shifted, some were completely absent while new ones were observed after adsorption. These changes are captured in Figure4b.The presence of new adsorption bands representing, alkyl halides, alkenes, alkynes, amino and nitro compounds was attributed to chemical reactions of adsorbing material and the adsorbent [24]. Due to displacement of the carboxyl and hydroxyl groups, band at $1154.61 \mathrm{~cm}^{-1}$ and $722.04 \mathrm{~cm}^{-1}$ depicting $\mathrm{CH} 2$-I group and $\mathrm{C}-\mathrm{Cl}$ stretch respectively [5] were also observed. The peaks at $1026.16 \mathrm{~cm}^{-1}$ and $3216.41 \mathrm{~cm}^{-1}$ representing $\mathrm{CO}$ and $\mathrm{OH}$ lost their intensity perhaps, due to their participations in the adsorption process [24]. 


\subsection{Kinetics of PAH Adsorption and Breakthrough Curves}

Breakthrough patterns of PAH substances through various packed columns of ACP and APP observed with respect to changes in bed heights and flow rates were represented in the breakthrough curves. The apparent curve steepness variations observed among different bed heights are attributable to differences in breakthrough times of wastewater through various bed height columns or exhaustion times of bed materials because it took longer time for the PAH polluted wastewater to breakthrough the high bed height column due to long contacts with bed materials. Also, in high bed height, large surface area of the adsorbent material is usually provided which makes binding sites available for adsorption [20]. This implies that there was fast wave front movement of the PAH polluted wastewater through the mass transfer zone towards the column outlet of the $6 \mathrm{~cm}$ bed height but wave front movement progressively declined with increasing bed height from 9 to $12 \mathrm{~cm}$. In other words, increase in column bed height increased the mass transfer zone that is, creating a longer distance for the mass transfer zone to reach the exit. The prolonged area of coverage by the mass transfer zone created more interaction of PAH compounds with the bed materials. Hence the coverage and interaction with ACP and APP adsorbents subsequently resulted to more PAH compounds being adsorbed on the high bed material heights of 9 and $12 \mathrm{~cm}$ as depicted by the steepness of the breakthrough curves shown on Figures 7a-b. The reduction in the steepness of the breakthrough curves from that of $6 \mathrm{~cm}$ to $12 \mathrm{~cm}$ through $9 \mathrm{~cm}$ bed heights showed that PAH adsorption on the respective adsorbents increased at $9 \mathrm{~cm}$ to the highest at $12 \mathrm{~cm}$ bed height. On varying the in-flow rate, different breakthrough curve steepness was also observed. The apparent variations in the trend of breakthrough and breakthrough curve steepness are predicated on the amount of contact time the adsorbing material made with the adsorbents with consequent amount of material adsorbed. At high flow rate, PAH compound had limited time of contact with the ACP and APP adsorbents thereby resulting to low PAH adsorption on the adsorbents. On the other hand, the adsorbing materials made sufficient contacts with the adsorbent at low inlet flow rate by so doing engendering large PAH adsorption onto the adsorbents. Fitness of the breakthrough data was tested with YoonNelson, Adams Borhat and Thomas models. There were varying model parameters values for bed heights and in-flow rates. The seeming variations observed confirm different physico-chemical properties of the adsorbents and adsorbates and effects of various inputs on adsorption. The inverse relationships of the time required for $50 \%$ breakthrough with in-flow rates at constant bed heights further lend credence to low adsorption of PAH compounds at high flow rate. However, the high correlation $\left(\left(R^{2}\right)\right.$ values showed good agreement of the breakthrough data with the Yoon-Nelson model. The difference in the model parameters for Thomas model(maximum uptake capacity $\left(q_{o}\right)$ and rate constants $\left.\left(K_{t h}\right)\right)$ and that of Adams Bohart model $\left(\left(K_{A B}, N_{o}\right)\right.$ is attributed to variations in the physical properties of the adsorbents. The direct and inverse relationships of $\left(q_{o}\right)$ and $K_{t h}$ and $\left(K_{A B}, N_{o}\right)$ with in-flow rates of PAH solutions respectively is similar to what obtained in the previous studies[21], [18]. Adams Bohart, Yoon-Nelson and Thomas model parameter Values are higher in the study of Asiagwu,(2012) [13], Olayiwola,(2013) [21] and Parvathi et al (2011) [23] than the present study. This can be attributed to different adsorbate properties. High values of Coefficient of correlation indicate the suitability of the model to the breakthrough data. The good correlation also implies negligible axial dispersion of the PAH compounds under study on ACP and APP adsorbents and indicates that mass transfer at the surface, controlled the sorption process [20]

\section{Conclusion}

The study explored the viability of activated plantain and cassava peels to reduce the PAH compounds in a polluted wastewater. There were glaring differences in the physical 
and chemical characteristics of the adsorbents especially in their functional groups and number and sizes of the pores which determines the adsorption sites. The activated adsorbents reasonably reduced the concentrations of the PAH compounds in the wastewater. Comparing the two adsorbents, activated cassava peel (ACP) proved more efficient than the activated plantain peel(APP). The seeming variations in the removal efficiency of the two adsorbents were largely attributed to differences in their properties. Certain input variables (bed heights and flow rates) were adopted to study the adsorption of various PAH compounds (adsorbing materials) through breakthrough curves. Whereas the high flow rates produced high steeped curves, high bed heights of the adsorbents, on the other, created low steeped curves due to long migration distance.Variations in bed height of various adsorbents affected the sorption of the adsorbing materials directly. But, inverse relationship was observed with inflow rate of PAH solutions with adsorption. Yoon-Nelson, Adam-Bohart and Thomas models were used to describe the level of correlation of the data with the models. The models showed reasonable agreement with the data.

\section{References}

[1] G. Witt, "Polycyclic aromatic hydrocarbons in water and sediment of the Baltic Sea Marine Pollution Bulletin”, vol. 31, no. 2, (1995), pp. 37-248.

[2] M. Charlesworth, M.Service and C.E. Gibson, "PAHs contamination of Irish sediments", Marine pollution Bulletin, vol. 44, (2002), pp. 1421-1424.

[3] T. Nielsen, "Traffic Contribution of Polycyclic aromatic hydrocarbons in the center of a large city", Atmospheric Environment, vol. 30, (1996), pp. 3481-3490

[4] L.H. Keith and W.A Telliard, "Priority Pollutants", A perspective view. Environmental Science and Technology, vol. 13, (1979), pp. 416-423

[5] K. Skupinska, I. Misiewiczand and T. Kasprzycka-Guttman, "Polycyclic Aromatic Hydrocarbons: Physicochemical properties, Environmental Appearance and Impact on living organisms", Acta Poloniae pharmaceutica-Drug Research, vol. 61, no. 3, (2004), pp. 233-240.

[6] R. Eisler, "Polycyclic Aromatic Hydrocarbon hazards to fish and wildlife, and invertebrates: a synoptic review", US. Fish and Wildlife service, Biology Report, vol. 85, 1.110.81, (1987), pp.

[7] D. Lin, Y. Tu and L. Zhu, "Concentrations and health risk of polycyclic aromatic hydrocarbons in tea", Food and chemical Toxicology, vol. 43, (2005), pp. 41-48.

[8] J. Prycek, M. Ciganek and Z. Srinek, "Clean up of Extracts for Intracid Derivatives of Polycyclic Aromatic Hydrocarbons Analysis Prior their Gas Chromatography Determination", Journal of Brazillian Chemical Society, vol. 18 , no. 6, (2007), pp. 1125-1131

[9] T.M. Elmorsi, "Equilibrium Isotherms and Kinetic Studies of Removal of Methylene Blue Dye by Adsorption onto Miswak Leaves as a Natural Adsorbent", Journal of Environmental Protection, vol. 2, (2011), pp. 817-827

[10] T. Li, B. Chen and L. Zhu, "Enhanced sorption of polycyclic aromatic hydrocarbons from aqueous solution by modified pine bark", Bioresource Technology, vol. 101, (2010), pp. 7307-7313.

[11] B. Chen, M. Yuana and H. Liu, "Removal of Polycyclic Aromatic Hydrocarbons from Aqueous Solution using Plant Residue Materials as a Biosorbent", Journal of Hazardous Materials, vol. 188, (2011), pp. 436-442.

[12] G. Annadurai, R.S. Juang and D.J. Lee, "Adsorption of heavy metals from water using banana and orange peels", Water Science and Technology, vol. 47, (2002), pp. 185-190.

[13] A.K. Asiagwu, "Sorption Kinetic of $\mathrm{Pb}$ (II) and Cd (II) ions via Biomass Surface of Plantain Peel Waste", Bioadsorbents, vol. 13, no. 2, (2012), pp. 626-635

[14] A. Patrick Uzoije, L. O. Uzoigwe and C.I.O. Kamalu, "Activated Orange Meso-Carp Carbon (AOMC); An Acceptable Remediation Techniques for Crude Oil Pollution Effect", Research Journal of Applied Sciences, Engineering and Technology, vol. 4, no. 1, (2012), pp. 51-58.

[15] 1A.P. Uzoije, A. Onunkwo-A and N. Egwuonwu, "Crude Oil Sorption onto Groundnut Shell Activated Carbon", Research Journal of Environmental and Earth Sciences, vol. 3, no. 5, (2011), pp. 555-563

[16] A.P. Uzoije, J. Okolie, P.C. Njoku and U. Enwereuzo, "Adsorption of Copper (ii) ion on Heterogenous Surfaces of Selected Low-Cost Precursors; An Application of Isotherm, Thermodynamic and Kinetic models", Journal of Multidisciplinary Engineering Science and Technology (JMEST) ISSN:3159-0040, vol. 2, issue 1, (2015).

[17] B. Chen, M. Yuana and H. Liu, "Removal of Polycyclic Aromatic Hydrocarbons from Aqueous Solution using Plant Residue Materials as a Biosorbent”, Journal of Hazardous Materials, vol. 188, (2011), pp. 436-442. 
[18] J.A.O Oyekunle, E.H. Umukoro, O. Owoyomi, A.O.. Ogunfowokan and I.A Oke, "Adsorption Equilibruim, Kinetics and Thermodynamics of Cd(ii) removal from Synthetic Wastewater using Plantain Peel Charcoal", International Journal of Engineering Research and Application, vol. 3, no. 5, (2013), pp. 1961-1971.

[19] B.O. Opeolu and O.S. Fatoki, "Dynamics of Zinc sorption from aqueous matrices using plantain (Musa sp.) Peels biomass: African Journal of Biotechnology”, vol. 11, no. 68, (2012), pp. 13194-13201

[20] A.P Uzoije, C.I.O Kamalu and B. Uzuakpundu, "Adsorption Kinetics and Mechanisms of Cypermethrin and Dichlorovos on Heterogenous Activated Carbon Porous Media", Open Access Library Journal.http://dx.doi.org/10.4236/oalib.1101988, (2015b).

[21] O.O. Olayiwola, "Economic of Cassava Peel Activated Carbon In Treatment of Effluent From Cassava Processing Industry", International Monthly Refered Journal of Research in Management and Technology, vol. 2, (2013), pp. 69-76.

[22] K. Moses Oghenejoboh1, S. Orode Otuagoma and E. Onogwharitefe Ohimor, "Application of Cassava Peels Activated Carbon in the Treatment of Oil Refinery Wastewater - a Comparative Analysis", Journal of Ecological Engineering, vol. 17, no. 2, (2016), pp. 52-58

[23] C. Parvathi, T. Maruthavanan, S. sivamani and. C. Prakash, "Biosorption Studies for the Removal of Malachite Green from its Aqueous Solution by Activated Carbon Prepared from Cassava Peel EJournal of Chemistry", vol. 8, no. S1, (2011), pp. S61-S66

[23] B.H. Hameed and A.A Ahmad, "Batch adsorption of methylene blue from aqueous solution by garlic peel, an agricultural waste", Journal of Hazardous Materials, vol. 164, (2009), pp. 870-875.

[24] B.H. Hameed and M.l El-khaiary, "Removal of basic dye from aqueous medium using a novel waste material pumpkin seed hull”, Journal of Hazardous Materials, vol. 155, (2008), pp. 601-609.

\section{Authors}

Atulegwu Patrick Uzoije, he received bachelor of chemical engineering in 1996 at Enugu state university of technology. Subsequently, he specialized in Environmental Engineering with a master's degree obtained from University of Port Harcourt in $2000 \mathrm{He}$ later obtained his ph.D degree in Environmental Engineering in 2008 at University of Nigeria Nsukka. He is a registered engineer with Nigerian society of engineers and equally a member of other professional organizations like; Nigerian environmental society, Chemical society of Nigeria and Nigerian society of chemical engineers. Atulegwu Patrick Uzoije is currently an instructor and a researcher in the federal university of Technology Owerri.

Alex-Okorafor Chiwuike, he obtained a bachelor of science in micro=biology from university of calabar Nigeria. He subsequently got a master's degree in Environmental Technology with bias in pollution from Federal University of Technology Owerri Nigeria. Alex-Okorafor is being considered for ph.D program admission in the same school while he is assisting in the research laboratory for smooth running of practical works. 
International Journal of Advanced Science and Technology

Vol.111 (2018) 